\title{
Melatonin enhances arsenic trioxide-induced cytotoxicity by modulating autophagy in an acute promyelocytic leukemia cell line
}

\author{
Xia Wei, Xin Pu, Sainan Yang, Xiaoqin Meng, Xue Chen, Zhihua Zhang, Xaomin Sheng, Dan Xiang, \\ Yong Zhang \\ Department of Hematology, The Third Affiliated Hospital of Chongqing Medical University (Gener Hospital), Chongqing 401120, China \\ Contributions: (I) Conception and design: X Wei, Y Zhang; (II) Administrative support: Y Zhang; (III) Provision of study materials or patients: X Wei, \\ X Pu, S Yang, X Meng, X Chen; (IV) Collection and assembly of data: Z Zhang, X Sheng, D Xiang; (V) Data analysis and interpretation: X Wei; (VI) \\ Manuscript writing: All authors; (VII) Final approval of manuscript: All authors. \\ Correspondence to: Yong Zhang. Department of Hematology, The Third Affiliated Hospital of Chongqing Medical University (Gener Hospital), \\ Chongqing 401120, China. Email: 651064@cqmu.edu.cn.
}

Background: Arsenic trioxide (ATO)-containing therapeutic strategies are widely used in the treatment
of acute promyelocytic leukemia (APL). Growing evidence has shown that melatonin enhances the radio-
or chemo-sensitivity of numerous cancer cells. However, whether melatonin is capable of enhancing the
cytotoxic effects of ATO in APL cells remains unknown.
Methods: The present study conducted a $24 \mathrm{~h}$ melatonin exposure followed by additional 12,24 or
48 h ATO exposure in the APL cell line NB4 with or without autophagy-related protein 7 (ATG7)
silencing by RNA interference. Cell cytotoxicity was evaluated by Cell Counting Kit-8 (CCK-8) and lactate
dehydrogenase (LDH) assays. Cell apoptosis was assessed by Annexin-V/propidium iodide assay and western
blotting against cleaved caspase 3, Bax and Bcl-2. Autophagy was evaluated by western blotting against LC3.
Results: Pre-treatment with a non-cytotoxic dose of melatonin significantly enhanced ATO-mediated
reduced cell viability and increased LDH release. Furthermore, melatonin pre-treatment also enhanced
ATO-mediated increase in early and late apoptosis, as well as the expression of Bax and cleaved caspase 3,
while further decreasing ATO-mediated reduced expression of Bcl-2. Concomitantly, melatonin
pre-treatment increased LC3II expression and enhanced the ATO-mediated elevation in LC3II expression.
However, autophagy inhibition by ATG7 silencing blocked the enhancing effects of melatonin on ATO-
induced apoptosis and cytotoxicity. These findings indicated that melatonin pre-treatment enhances ATO-
induced cytotoxicity by modulating ATG7-mediated autophagy.

Conclusions: Melatonin could represent a valuable adjuvant to ATO in APL treatment, particularly in patients with ATO-resistant APL.

Keywords: Acute promyelocytic leukemia (APL); arsenic trioxide (ATO); melatonin; cytotoxicity; autophagy

Submitted May 02, 2019. Accepted for publication Sep 04, 2019.

doi: $10.21037 /$ tcr.2019.09.26

View this article at: http://dx.doi.org/10.21037/tcr.2019.09.26

\section{Introduction}

Acute promyelocytic leukemia (APL) belongs to the M3 subtype of acute myeloid leukemia, which is driven by the $\mathrm{t}(15 ; 17)(\mathrm{q} 22 ; \mathrm{q} 21)$ chromosomal translocation, which results in the promyelocytic leukemia-retinoic acid receptor
(PML/RAR $\alpha$ ) fusion gene (1). The prognosis for patients with APL has improved in recent decades following the application of arsenic trioxide (ATO) and all-trans retinoic acid (ATRA)-based therapies (2,3). Trisenox is an approved drug containing ATO and has been used successfully in 
patients with relapsed and refractory APL, either alone or in combination with ATRA, where it may achieve maximum survival rates and nearly complete remission. Regarding their mechanism of action, ATRA mainly promotes cell differentiation, whereas ATO primarily induces cell apoptosis in APL cells $(4,5)$. Despite the great efficacy for low-risk APL, many patients with high-risk APL may remain resistant to ATRA or ATO (6). Accordingly, the development of novel synergistic chemicals for the treatment of ATRA or ATO-resistant APL is of great importance.

As the main product of the pineal gland, melatonin has been shown to exert anti-proliferative, anti-oxidant and anti-inflammatory activities in multiple cell lines and animal models (7-9). Importantly, it has been reported that melatonin inhibits tumorigenicity, hinders cancer metastasis or exerts anti-tumor activity in various types of human cancer such as glioblastoma (10), breast cancer (11), colon cancer (12), hepatocellular carcinoma (13) and prostate cancer (14). Previous studies have demonstrated that disturbances in the nocturnal secretion of melatonin can make tumors insensitive to tamoxifen treatment (15), whereas melatonin administration enhances the radiosensitivity of human breast cancer cells by modulation of proteins involved in estrogen biosynthesis (16). It has also been shown that melatonin increases the cytotoxicity of sorafenib in human hepatocellular carcinoma cells by increasing the levels of oxidative stress and mitophagy activation (17). However, whether melatonin could increase the cytotoxic effects of ATO in APL cells remains unclear.

Autophagy is an intracellular degradation process that eliminates damaged organelles or proteins by the hydrolysis of engulfed autophagosomal materials through the involvement of lysosomal enzymes (18). It is well documented that autophagy serves a critical role in cell homeostasis in response to cellular stress, including nutrient limitation, hypoxia and chemotherapy (19). In cancer cells, autophagy can maintain cell survival by inhibition of caspase-dependent apoptosis (20), while over-activation of autophagy may lead to programmed cell death (21). Thus, the role of autophagy in cancer cells is markedly complex and has both pro-survival and pro-mortality effects in different types of cancer (22). Previous studies have revealed that melatonin and ATO could over-activate autophagy and trigger cell apoptosis $(23,24)$. Nevertheless, whether melatonin can sensitize APL cells to ATO by modulating autophagy is largely unknown.

In view of the above considerations, the present study aimed to explore the effects of melatonin on ATO-induced cytotoxicity in the human APL NB4 cell line and to unravel the mechanisms involved.

\section{Methods}

\section{Cell culture}

The human APL NB4 cell line was purchased from the Shanghai Institutes for Biological Sciences of the Chinese Academy of Sciences (Shanghai, China). The cells were cultured in RPMI 1640 (Gibco; Thermo Fisher Scientific, Inc., Waltham, MA, USA) containing $0.5 \mathrm{mM} \mathrm{L}$-glutamine, $4.5 \mathrm{~g} / \mathrm{L}$ glucose, $110 \mathrm{mg} / \mathrm{L}$ sodium pyruvate, $10 \%$ fetal bovine serum (FBS) (Gibco; Thermo Fisher Scientific, Inc.) and $100 \mathrm{U} / \mathrm{mL}$ penicillin-streptomycin (Sigma-Aldrich; Merck KGaA, Darmstadt, Germany) in a $37{ }^{\circ} \mathrm{C}$ incubator containing $5 \% \mathrm{CO}_{2}$. This study had been approved by the Ethics Committee of Third Affiliated Hospital of Chongqing Medical University (No.2019-24).

\section{Treatment}

A $100 \mathrm{mM}$ stock solution of ATO (Sigma-Aldrich; Merck $\mathrm{KGaA}$ ) was prepared with deionized water, whereas the 10 $\mathrm{mM}$ stock solution of melatonin (Sigma-Aldrich; Merck KGaA) was prepared with dimethyl sulfoxide (SigmaAldrich; Merck KGaA). Prior to administration, the stock solutions were diluted in fresh PRMI 1640 medium. Subsequently, $5 \times 10^{4}$ cells $/ \mathrm{ml}$ in logarithmic growth phase were pre-exposed to $1 \mathrm{mM}$ melatonin (freshly prepared in RPMI 1640 medium) for $24 \mathrm{~h}$. Then, the melatonincontaining medium was removed and medium containing 0 or $2 \mu \mathrm{M}$ ATO was added for additional 12, 24 or $48 \mathrm{~h}$.

\section{$R N A$ interference}

Autophagy-related protein 7 (ATG7)-small interference RNA (siRNA) (sc41445; Santa Cruz Biotechnology, Inc., Dallas, TX, USA) or a control siRNA (sc37007; Santa Cruz Biotechnology, Inc.) were dissolved into RPMI 1640 medium containing Lipofectamine 2000 (Invitrogen; Thermo Fisher Scientific, Inc.) and transfected into NB4 cells $\left(1 \times 10^{5}\right.$ cells $\left./ \mathrm{mL}\right)$ at a concentration of $100 \mathrm{pmol} / \mathrm{L}$. Cells were incubated for $24 \mathrm{~h}$ before further treatment.

\section{Cytotoxicity assays}

The viability of NB4 cells was determined by Cell 
Counting Kit-8 (CCK-8) assays (Dojindo Molecular Technologies, Inc., Kumamoto, Japan). Briefly, cells were seeded into a 96-well plate at a density of $5 \times 10^{4}$ cells $/ \mathrm{mL}$. Upon treatment with ATO and/or melatonin, a mixture of $10 \mu \mathrm{L}$ CCK-8 solution and $90 \mu \mathrm{L}$ RPMI 1640 medium was added to the cells and incubated for $2 \mathrm{~h}$ at $37^{\circ} \mathrm{C}$. An Infinite M200 Microplate Reader (Tecan Group, Ltd., Mannedorf, Switzerland) was next used to determine the optical density (OD) values at $450 \mathrm{~nm}$. At least 3 replicates were conducted in each experiment. The values were expressed as a percentage of the control.

The Cytotoxicity Detection kit (Roche Diagnostics GmbH, Mannheim, Germany) was used according to the manufacturer's instructions in lactate dehydrogenase $(\mathrm{LDH})$ release assays in order to evaluate the cytotoxicity of melatonin and/or ATO. Briefly, upon treatment with ATO and/or melatonin, cell-free culture supernatants were collected and incubated with an LDH solution for $30 \mathrm{~min}$ at $25^{\circ} \mathrm{C}$. The Infinite M200 Microplate Reader (Tecan Group, Ltd.) was used to detect the OD values at $490 \mathrm{~nm}$. At least 3 replicates were conducted in each experiment. The values were expressed as a percentage of the control.

\section{Western blotting}

NB4 cells were seeded at a density of $5 \times 10^{4}$ cells $/ \mathrm{mL}$. Following treatment, cells were lysed with lysis buffer (Beyotime Institute of Biotechnology, Haimen, China) containing phosphatase and protease inhibitors (Roche Diagnostics $\mathrm{GmbH}$ ) following $30 \mathrm{~min}$ of incubation at $4{ }^{\circ} \mathrm{C}$, and then scraped off on ice. Subsequently, supernatants were obtained by centrifugation at $15,000 \times \mathrm{g}$ for $20 \mathrm{~min}$, and a BCA Protein Assay kit (Beyotime Institute of Biotechnology) was used to determine the concentration of the collected proteins. In total, $60 \mu \mathrm{g}$ total protein from each group was loaded onto a $10 \%$ SDS-polyacrylamide gel for electrophoresis. Next, the proteins were transferred to nitrocellulose membranes (Bio-Rad Laboratories, Inc., Hercules, CA, USA), which were blocked with non-fat powdered milk (5\%) at room temperature for $2 \mathrm{~h}$, followed by incubation with primary antibodies targeting Bax (2772; 1:1,000; Cell Signaling Technology, Inc., Danvers, MA, USA), Bcl-2 (2876; 1:1,000; Cell Signaling Technology, Inc.), caspase 3 (ab13847; 1:1,000; Abcam, Cambridge, UK), LC3 (ab48394; 1:1,000; Abcam), ATG7 (ab133528; 1:1,000; Abcam) or GAPDH (1:1,000, Sigma-Aldrich, Merck KGaA) overnight at $4{ }^{\circ} \mathrm{C}$ with gentle shaking. The next day, the membranes were washed and incubated with a horseradish peroxidase-conjugated anti-mouse or anti-rabbit secondary antibody (1:2,000; Abcam) at room temperature for $2 \mathrm{~h}$. Then, the blots were evaluated with a chemiluminescence system (GE Healthcare Bio-Sciences, Pittsburgh, PA, USA) and quantified with an analysis software (Bio-Rad Laboratories, Inc.).

\section{Annexin-V/fluorescein isothiocyanate (FITC) assay}

An Annexin V-FITC/propidium iodide (PI) apoptosis kit (BD Biosciences, Franklin Lakes, NJ, USA) was used to detect apoptosis according to the manufacturer's instructions. Following melatonin and/or ATO treatments, the cells were washed and incubated with Annexin V-FITC $(5 \mu \mathrm{L})$ and PI $(5 \mu \mathrm{L})$ for $10 \mathrm{~min}$ in the dark at room temperature. A flow cytometer (Beckman Coulter, Inc., Brea, CA, USA) was used to determine the apoptotic rate. Total apoptosis was quantified including early apoptotic cells (Annexin V-FITC ${ }^{+}, \mathrm{PI}^{-}$) and late apoptotic cells (Annexin $\mathrm{V}$-FITC ${ }^{+}, \mathrm{PI}^{+}$).

\section{Statistical analysis}

Statistical significant differences were determined with SPSS 17.0 software (SPSS Inc., Chicago, IL, USA). Oneway analysis of variance with Tukey's post hoc test was performed. Data were expressed as the mean \pm standard error of mean (SEM) from 3 independent experiments. $\mathrm{P}<0.05$ was considered to indicate a statistically significant difference.

\section{Results}

\section{Melatonin pre-treatment enhanced ATO-induced cytotoxicity in NB4 APL cells}

ATO treatment at $\geq 0.5 \mu \mathrm{M}$ reduced cell viability in NB4 APL cells in a dose- and time-dependent manner. There was $>50 \%$ reduction in cell viability following treatment with ATO at $2 \mu \mathrm{M}$ for $48 \mathrm{~h}$ (Figure $1 \mathrm{~A}$ ). By contrast melatonin treatment for $48 \mathrm{~h}$ did not affect cell viability at doses lower than $2 \mathrm{mM}$ (Figure 1B). Then, cells were pretreated with melatonin at $1 \mathrm{mM}$ for $24 \mathrm{~h}$ followed by ATO treatment at $2 \mu \mathrm{M}$ for additional 12, 24 or $48 \mathrm{~h}$. Compared with the control group, no changes in cell viability were observed when the cells were treated with $1 \mathrm{mM}$ melatonin alone. However, the cell viability in the melatonin + ATO group was significantly lower than that in the ATO 
A

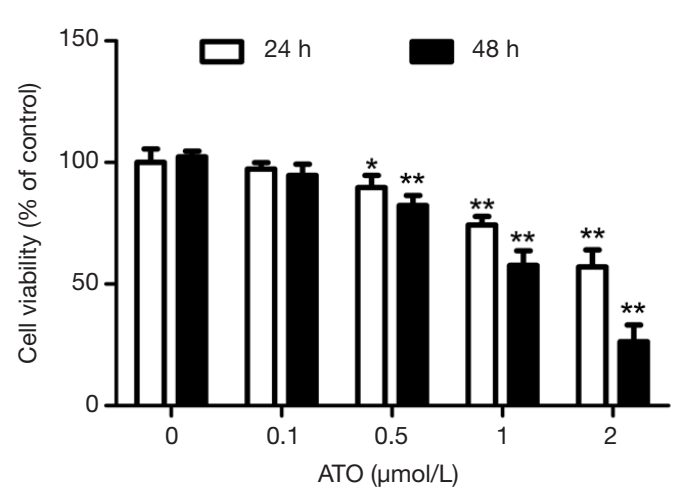

C

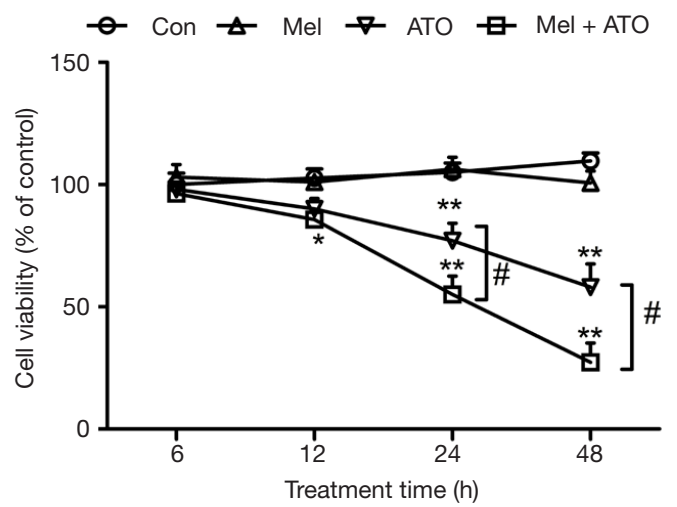

B
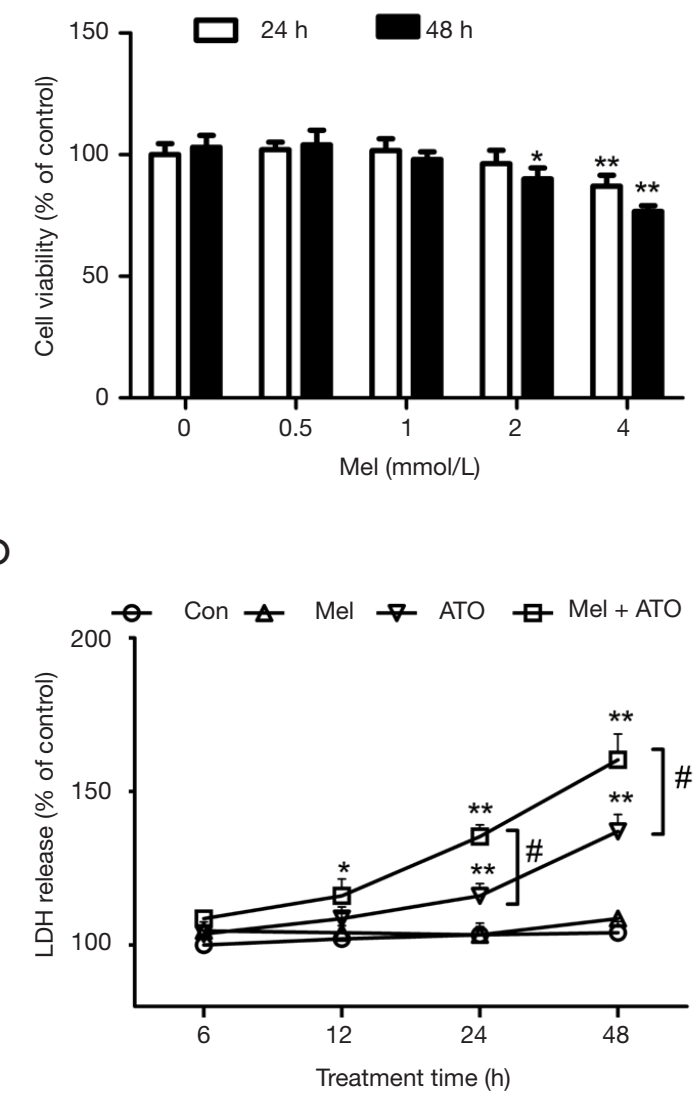

Figure 1 Effects of melatonin and ATO treatment, alone or in combination, on cellular cytotoxicity and LDH release in NB4 cells. Cell viability was evaluated in cells treated with (A) 0, 0.1, 0.5, 1 and $2 \mu \mathrm{M}$ ATO or (B) 0, 0.5, 1, 2 and $4 \mathrm{mM}$ melatonin for 24 or $48 \mathrm{~h}$. (C) Cell viability and (D) LDH levels were determined in cells pre-treated with $1 \mathrm{mM}$ melatonin followed by $2 \mu \mathrm{M}$ ATO treatment for additional 6, 12, 24 and $48 \mathrm{~h}$. Values are expressed as the mean \pm standard error of the mean from $\geq 3$ independent experiments. ${ }^{*} \mathrm{P}<0.05$, ${ }^{*} \mathrm{P}<0.01$ compared with the control groups; ${ }^{\#} \mathrm{P}<0.05$ compared with the ATO alone-treated group. ATO, arsenic trioxide; LDH, lactate dehydrogenase.

treatment group at 24 and $48 \mathrm{~h}$ (Figure 1C). Consistently, the LDH release levels, which are indicative of cell death, was not altered in the melatonin pre-treatment alone group compared with the control group. However, the levels of $\mathrm{LDH}$ release in the melatonin + ATO group were higher than those in the ATO treatment group at 24 and $48 \mathrm{~h}$ (Figure 1D).

\section{Melatonin pre-treatment facilitates ATO-induced apoptosis in NB4 APL cells}

The results from the Annexin-V/FITC assay revealed that ATO treatment at $2 \mu \mathrm{M}$ for $48 \mathrm{~h}$ significantly increased the early and late apoptotic rate, while melatonin pre-treatment revealed pro-apoptotic effects, with the apoptotic rate in the melatonin + ATO group being significantly higher than that in the ATO group (Figure 2A,B).

Caspase- 3 is one of the most important markers during apoptosis. Therefore, the present study explored whether melatonin pre-treatment aggravated ATO-induced cytotoxicity through caspase signaling. The results from western blotting demonstrated that the expression levels of cleaved caspase 3 were not affected by melatonin pretreatment alone, whereas melatonin enhanced the ATOinduced expression of cleaved caspase 3 (Figure 2C). It has been reported that numerous proteins such as Bax and Bcl-2 are involved in the regulation of the caspasedependent initiation of apoptosis (22). In the present study, ATO treatment increased the levels of Bax expression and reduced the expression levels of Bcl-2; however, the level 
A

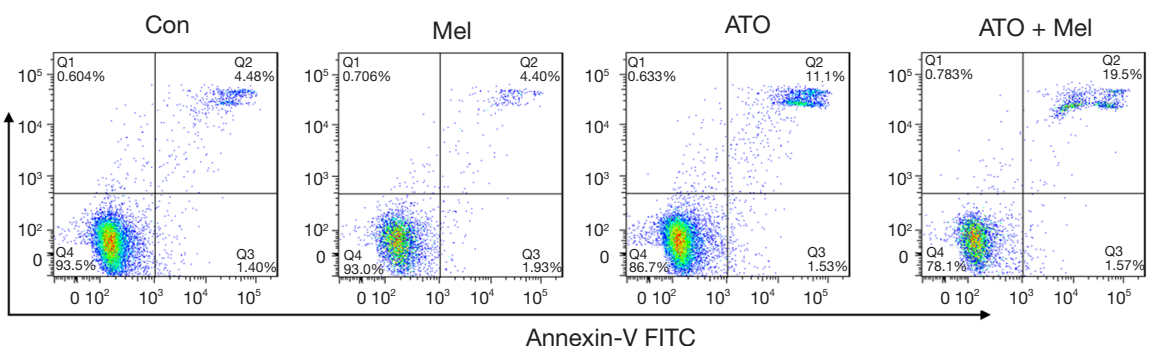

B
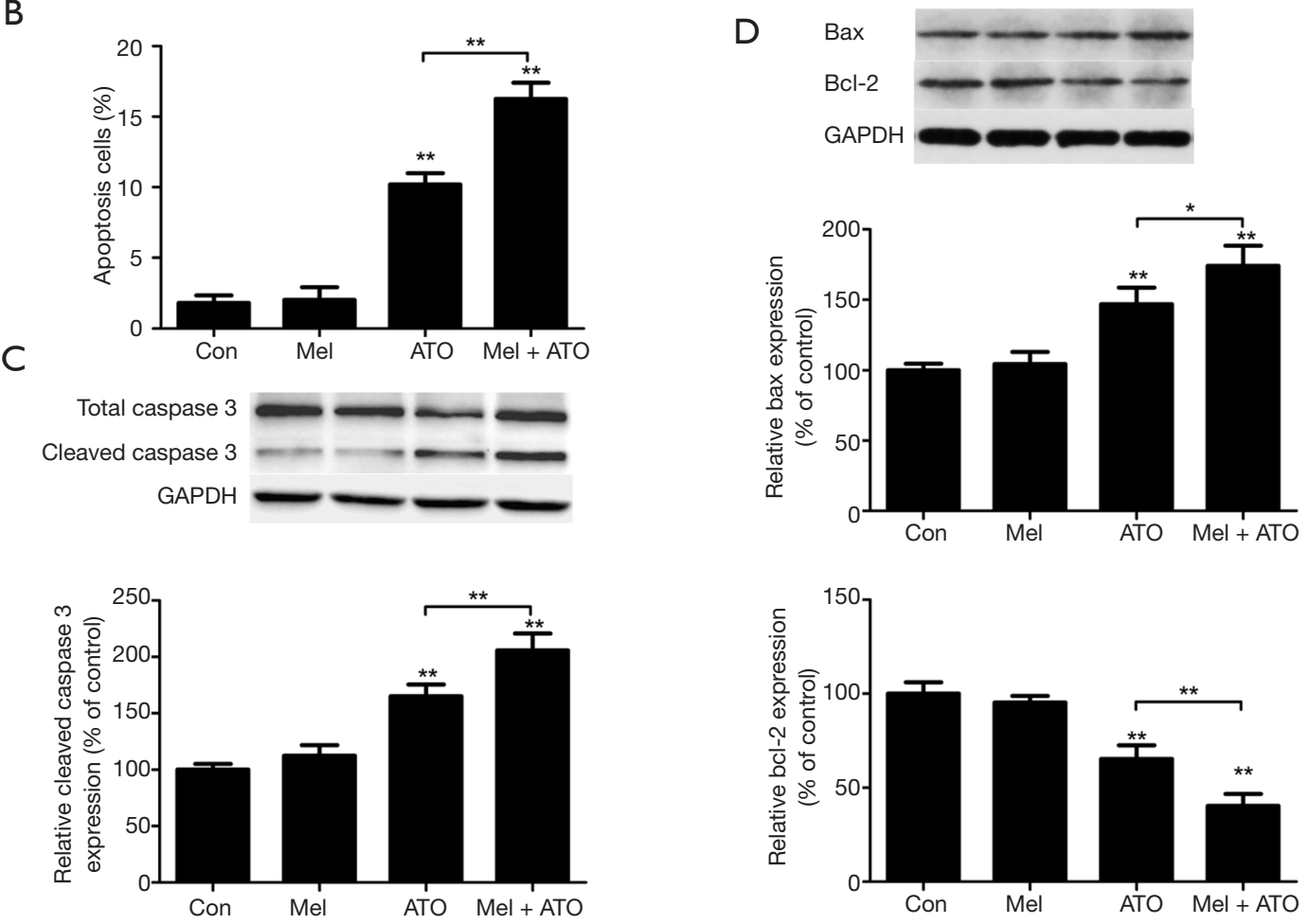

Figure 2 Effects of melatonin and ATO treatment, alone or in combination, on the expression levels of apoptosis-related proteins in NB4 cells. Cells were pre-treated with $1 \mathrm{mM}$ melatonin with or without $2 \mu \mathrm{M}$ ATO treatment for additional $48 \mathrm{~h}$. (A) Representative images of Annexin V/propidium iodide staining. (B) Annexin V positive cells, indicative of early and late apoptosis, were quantified. (C) Representative images and quantitative analysis of caspase 3 and cleaved caspase 3 expression, as detected by western blotting. (D) Representative images and quantitative analysis of the expression levels of Bax and Bcl-2. The ratio of cleaved caspase 3/total caspase 3 was calculated. GAPDH was used as the internal control. Value are expressed as the mean \pm standard error of the mean $(\mathrm{n}=3),{ }^{*} \mathrm{P}<0.05$ and ${ }^{* *} \mathrm{P}<0.01$ compared with the control or indicated groups. ATO, arsenic trioxide.

of Bax in the melatonin + ATO group was higher than that in the ATO group, while the level of Bcl-2 in the melatonin + ATO group was lower than that in the ATO group (Figure 2D).

\section{ATG7 silencing blocks the enhancing effects of melatonin on ATO-induced apoptosis in NB4 APL cells}

Compared with the control group, both melatonin and
ATO treatments increased the expression of LC3II, while cells in the melatonin + ATO group exhibited higher expression of LC3II than those treated with melatonin or ATO alone (Figure $3 A, B$ ). In order to evaluate the involvement of autophagy, ATG7 was silenced using RNA interference. The efficiency of silencing ATG 7 was $\sim 70 \%$ (Figure S1). Notably, ATG7 silencing significantly blocked the increase in LC3II levels in the ATO-treated or 
A

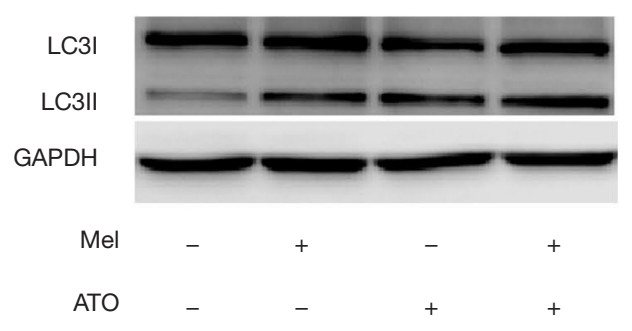

C

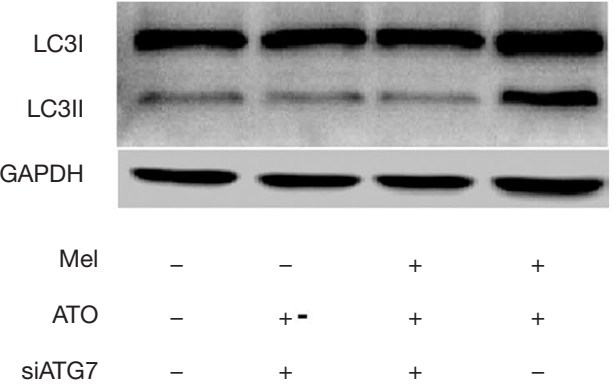

$\mathrm{E}$

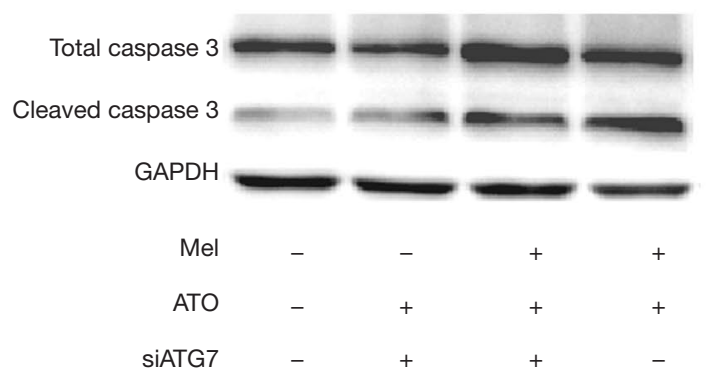

B

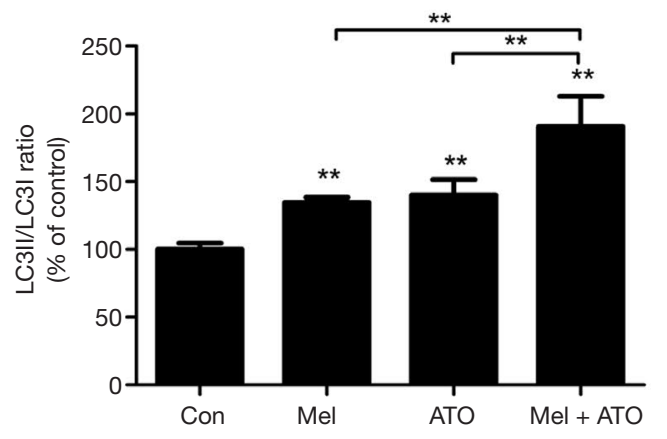

D

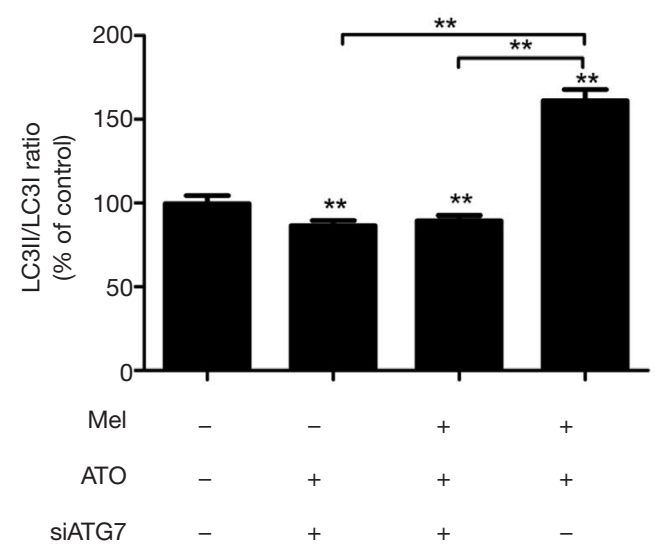

$\mathrm{F}$

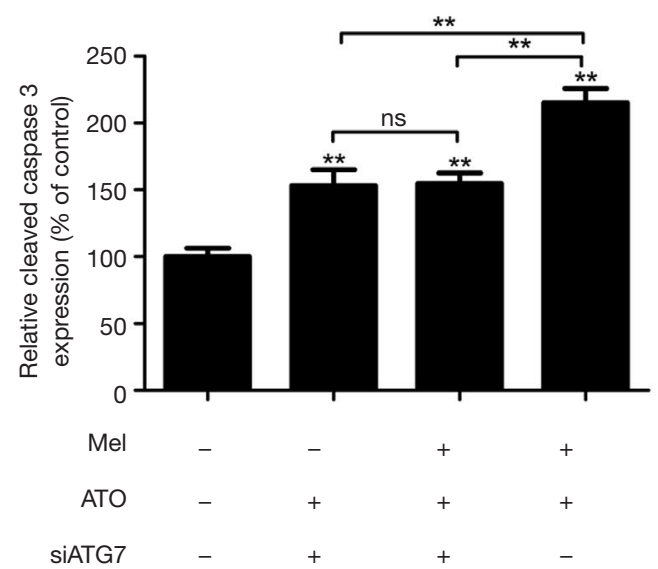

Figure 3 Effects of melatonin and ATO treatment, alone or in combination, on autophagy and apoptosis in NB4 cells with or without ATG7 silencing. Cells were treated as described in Figure 2. Autophagy inhibition was performed by ATG7 RNA interference. Representative images (A) and quantitative analysis (B) showing the expression levels of LC3 upon treatments with melatonin, ATO or their combinations, (C,D) with or without ATG7 silencing, and (E,F) the expression levels of caspase 3 and cleaved caspase 3 in cells treated with melatonin and/ or ATO with or without ATG7 silencing. The ratio of cleaved caspase 3/total caspase 3 was calculated. GAPDH was used as the internal control. Each value is expressed as the mean \pm standard error of the mean $(n=3)$. ${ }^{*} \mathrm{P}<0.05$ and ${ }^{* *} \mathrm{P}<0.01$ compared with the control or indicated groups. ns, no statistically significant difference; ATO, arsenic trioxide; ATG7, autophagy-related protein 7; LC3, light chain 3. 
A

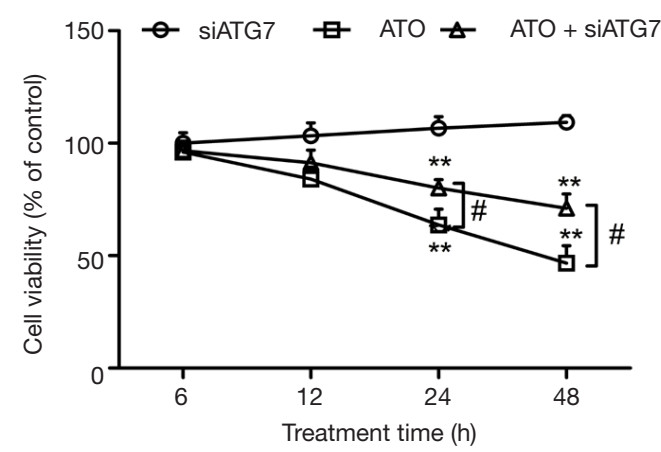

C

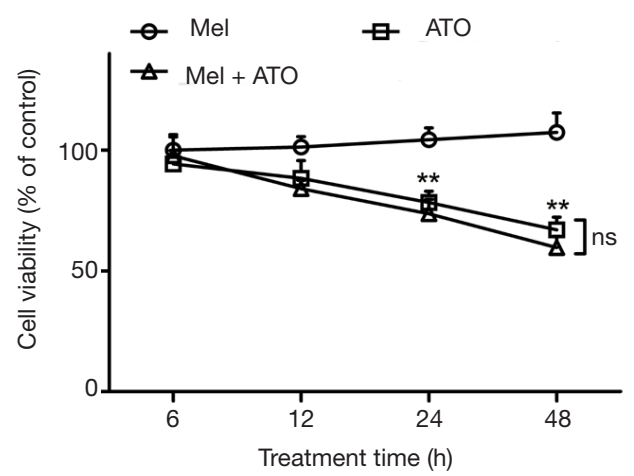

B

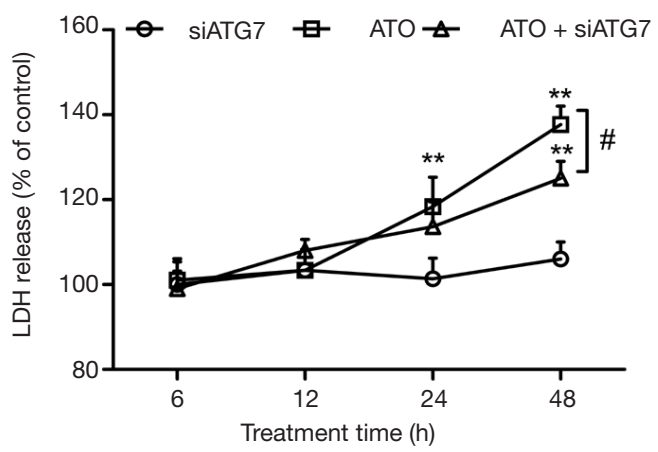

D

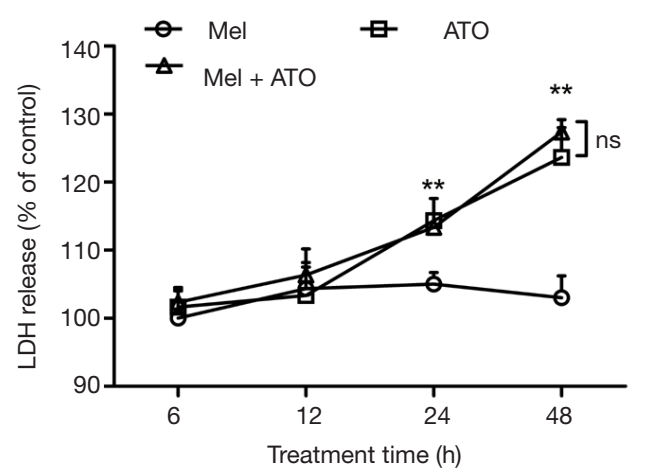

Figure 4 Effects of ATG7 silencing on the cytotoxicity of ATO treatment with or without melatonin pre-treatment. (A) Cell viability and (B) LDH levels were determined in cells treated with $2 \mu \mathrm{M}$ ATO with or without ATG7 silencing. (C) Cell viability and (D) LDH levels were determined in cells pre-treated with $1 \mathrm{mM}$ melatonin followed by $2 \mu \mathrm{M}$ ATO for additional $48 \mathrm{~h}$ with or without ATG7 silencing. Each value was expressed as the mean \pm standard error of the mean $(\mathrm{n}=3)$. ${ }^{* *} \mathrm{P}<0.01$ compared with the control groups; ${ }^{\#} \mathrm{P}<0.05$ compared with the indicated groups. ns, no statistically significant difference; ATO, arsenic trioxide; ATG7, autophagy-related protein 7; LDH, lactate dehydrogenase.

melatonin + ATO groups (Figure 3C,D). Of note, although the expression levels of cleaved caspase 3 in the melatonin + ATO groups and the efficiency of ATG7 silencing was higher in this group compared with the control group, the increase in cleaved caspase 3 levels in the melatonin + ATO group was significantly blunted. Furthermore, the former higher expression of cleaved caspase 3 in the melatonin + ATO group than that in the ATO group was eliminated following ATG7 silencing (Figure 3E,F).

\section{ATG7 silencing eliminates the enhancing effects of melatonin on ATO-induced cytotoxicity in NB4 APL cells}

A number of experiments were conducted to explore the role of autophagy in the enhancing effects of melatonin on ATO-induced cytotoxicity. The results from the CCK-8 assay revealed that ATG7 silencing significantly attenuated the ATO-induced reduction of cell viability (Figure $4 A$ ), as well as the ATO-induced elevation of $\mathrm{LDH}$ release (Figure 4B). Following ATG7 silencing, there were no differences in cell viability between the melatonin + ATO group and the ATO group (Figure 4C), so was the levels of LDH release (Figure 4D).

\section{Discussion}

Our results demonstrated that melatonin pre-treatment at a non-cytotoxic dose significantly enhanced ATOreduced cell viability and ATO-mediated increased LDH release in NB4 APL cells. Furthermore, melatonin pretreatment also enhanced ATO-increased expression of cleaved caspase 3 and Bax, and decreased ATO-mediated 
reduction in Bcl-2 expression. Concomitantly, melatonin pre-treatment increased LC3II expression and enhanced the ATO-mediated elevation in LC3II expression. However, autophagy inhibition by ATG7 silencing blocked the enhancing effects of melatonin on ATO-induced apoptosis and cytotoxicity. These findings indicated that melatonin pre-treatment enhanced ATO-induced cytotoxicity by modulating ATG7-mediated autophagy.

In recent years, benefits from ATO-containing therapeutic strategies in APL treatment had led to a great interest in ATO. Faster complete remission rates and fewer relapses have been observed in patients with APL receiving ATO treatment and ATRA induction compared with patients receiving standard ATRA chemotherapy (25). Despite this unprecedented success, numerous high-risk patients failed to completely achieve relapse or molecular remission and exhibited resistance to ATO therapy (26). It is widely accepted that a variety of mechanisms are involved in the resistance to anti-cancer therapies, including changes in the drug target, elevated drug biotransformation, enhanced drug efflux, increased DNA damage repair, overactive pro-survival signaling, reduced sensitivity to apoptosis and abnormal autophagy machinery (27). In patients with APL, the mutation in the arsenic binding domain of PML/ RAR $\alpha$ could result in arsenic resistance (28). Growing efforts have been made to identify potential drugs for enhancing the sensitivity of APL cells to ATO treatment, although unsuccessfully. Our finding demonstrated that melatonin pre-treatment significantly enhanced ATOinduced cytotoxicity in APL cells, which was consistent with the synergistic effect of melatonin and ATO on non-APL leukemic cells, as previously reported (29).

Physiologically, with normal light/dark conditions, melatonin is synthesized and secreted by the pineal gland at night (30). In USA, melatonin has been recommended as a dietary supplement and is sold as a food additive (31). At present, daily administration of melatonin is widely accessible, including patients with cancer. In the 1980s, the association between melatonin and cancer was established by observing the disturbed melatonin status in patients with cancer. Furthermore, the incidence of carcinogenesis was increased in pinealectomized animals, and this increased carcinogenesis was significantly alleviated by melatonin supplements (32-34). Further investigations revealed that working night shifts could contribute to the incidence of multiple cancers such as prostate, colorectal, endometrial, lung, gastric, ovarian and breast cancer. These results, along with the lower incidence of breast cancer observed in blind individuals or in those with higher levels of melatonin in urine indicated the critical role of melatonin during the incidence and progression of cancer (35).

The present study demonstrated that the mechanism involved in the melatonin-mediated enhanced anti-APL effects is the activation of autophagy, whereby targets such as macromolecules or organelles undergo lysosomal degradation (36). However, autophagy serves a dual role regarding the survival of cancer cells. It could increase tumor resistance to various types of chemotherapy and promote cell survival, while it could induce programmed cell death to facilitate the elimination of cancer cells. To date, various clinical trials have been conducted for increasing the cytotoxicity to cancer cells based on the synergistic effect of autophagy inhibitors alongside chemotherapy (37). One of such examples is the use of a histone deacetylase inhibitor to enhance the growth inhibition of tamoxifen-resistant MCF-7 cells by induction of autophagic cell death (38). Previous studies revealed that melatonin may also inhibit tumor regression in MCF-7 xenografts by inducing autophagy (15), which is consistent with the present study. In addition, melatonin treatment could increase the anticancer effects of sorafenib in hepatocellular carcinoma via mitophagy induction, which may be attributed to increased reactive oxygen species (ROS) production and mitochondrial dysfunction. It has been demonstrated that sorafenib plus melatonin could enhance the colocalization of lysosomes and mitochondria, and increase the levels of the mitophagy markers Parkin and PINK1, which could promote the degradation of mitochondria (17). Generally, the specific role of autophagy in cancer cells and the dual role of melatonin mainly depend on the type of cancer cells, surrounding environment and treatment pattern. Future studies are warranted to investigate the roles of melatonin in other cancer cells.

\section{Conclusions}

In conclusion, our results indicated that melatonin pretreatment enhances ATO-induced cytotoxicity in APL cells by modulating ATG7-mediated autophagy. Although further studies are necessary for exploring the detailed molecular mechanisms involved, our findings suggest that melatonin could represent a valuable adjuvant to ATO in APL treatment, particularly in ATO-resistant patients.

\section{Acknowledgments}

Special thanks to Prof. Minzhong Zhou for the guidance 
during the manuscript preparation.

Funding: None.

\section{Footnotes}

Conflicts of Interest: All authors have completed the ICMJE uniform disclosure form (available at http://dx.doi. org/10.21037/tcr.2019.09.26). The authors have no conflicts of interest to declare.

Ethical Statement: The authors are accountable for all aspects of the work in ensuring that questions related to the accuracy or integrity of any part of the work are appropriately investigated and resolved. This study was conducted in accordance with the Declaration of Helsinki (as revised in 2013). This study had been approved by the Ethics Committee of Third Affiliated Hospital of Chongqing Medical University (Gener Hospital) (No.201924). Individual informed consent was waived.

Open Access Statement: This is an Open Access article distributed in accordance with the Creative Commons Attribution-NonCommercial-NoDerivs 4.0 International License (CC BY-NC-ND 4.0), which permits the noncommercial replication and distribution of the article with the strict proviso that no changes or edits are made and the original work is properly cited (including links to both the formal publication through the relevant DOI and the license). See: https://creativecommons.org/licenses/by-nc-nd/4.0/.

\section{References}

1. de The H, Pandolfi PP, Chen Z. Acute Promyelocytic Leukemia: A Paradigm for Oncoprotein-Targeted Cure. Cancer Cell 2017;32:552-60.

2. Lo-Coco F, Avvisati G, Vignetti M, et al. Retinoic acid and arsenic trioxide for acute promyelocytic leukemia. $\mathrm{N}$ Engl J Med 2013;369:111-21.

3. Lo-Coco F, Di Donato L, Schlenk RF. Targeted Therapy Alone for Acute Promyelocytic Leukemia. N Engl J Med 2016;374:1197-8.

4. Brown G, Hughes P. Retinoid differentiation therapy for common types of acute myeloid leukemia. Leuk Res Treatment 2012;2012:939021.

5. Cicconi L, Breccia M, Franceschini L, et al. Prolonged treatment with arsenic trioxide (ATO) and all-transretinoic acid (ATRA) for relapsed acute promyelocytic leukemia previously treated with ATRA and chemotherapy.
Ann Hematol 2018;97:1797-802.

6. Coombs CC, Tavakkoli M, Tallman MS. Acute promyelocytic leukemia: where did we start, where are we now, and the future. Blood Cancer J 2015;5:e304.

7. Favero G, Franceschetti L, Bonomini F, et al. Melatonin as an Anti-Inflammatory Agent Modulating Inflammasome Activation. Int J Endocrinol 2017;2017:1835195.

8. Reiter RJ, Mayo JC, Tan DX, et al. Melatonin as an antioxidant: under promises but over delivers. J Pineal Res 2016;61:253-78.

9. Sanchez-Hidalgo M, Lee M, de la Lastra CA, et al. Melatonin inhibits cell proliferation and induces caspase activation and apoptosis in human malignant lymphoid cell lines. J Pineal Res 2012;53:366-73.

10. Chen X, Hao A, Li X, et al. Melatonin inhibits tumorigenicity of glioblastoma stem-like cells via the AKTEZH2-STAT3 signaling axis. J Pineal Res 2016;61:208-17.

11. Borin TF, Arbab AS, Gelaleti GB, et al. Melatonin decreases breast cancer metastasis by modulating Rhoassociated kinase protein-1 expression. J Pineal Res 2016;60:3-15.

12. Gao Y, Xiao X, Zhang C, et al. Melatonin synergizes the chemotherapeutic effect of 5-fluorouracil in colon cancer by suppressing PI3K/AKT and NF-kappaB/iNOS signaling pathways. J Pineal Res 2017;62. doi: 10.1111/ jpi.12380.

13. Sanchez DI, Gonzalez-Fernandez B, San-Miguel B, et al. Melatonin prevents deregulation of the sphingosine kinase/sphingosine 1-phosphate signaling pathway in a mouse model of diethylnitrosamine-induced hepatocellular carcinoma. J Pineal Res 2017;62. doi: 10.1111/jpi.12369.

14. Mayo JC, Hevia D, Quiros-Gonzalez I, et al. IGFBP3 and MAPK/ERK signaling mediates melatonin-induced antitumor activity in prostate cancer. J Pineal Res 2017;62. doi: 10.1111/jpi.12373.

15. Dauchy RT, Xiang S, Mao L, et al. Circadian and melatonin disruption by exposure to light at night drives intrinsic resistance to tamoxifen therapy in breast cancer. Cancer Res 2014;74:4099-110.

16. Alonso-Gonzalez C, Gonzalez A, Martinez-Campa C, et al. Melatonin enhancement of the radiosensitivity of human breast cancer cells is associated with the modulation of proteins involved in estrogen biosynthesis. Cancer Lett 2016;370:145-52.

17. Prieto-Dominguez N, Ordonez R, Fernandez A, et al. Melatonin-induced increase in sensitivity of human hepatocellular carcinoma cells to sorafenib is associated with reactive oxygen species production and mitophagy. J 
Pineal Res 2016;61:396-407.

18. Mizushima N, Komatsu M. Autophagy: renovation of cells and tissues. Cell 2011;147:728-41.

19. Yuan HX, Russell RC, Guan KL. Regulation of PIK3C3/ VPS34 complexes by MTOR in nutrient stress-induced autophagy. Autophagy 2013;9:1983-95.

20. Chen Y, Henson ES, Xiao W, et al. Tyrosine kinase receptor EGFR regulates the switch in cancer cells between cell survival and cell death induced by autophagy in hypoxia. Autophagy 2016;12:1029-46.

21. Marino G, Niso-Santano M, Baehrecke EH, et al. Selfconsumption: the interplay of autophagy and apoptosis. Nat Rev Mol Cell Biol 2014;15:81-94.

22. Liu LL, Long ZJ, Wang LX, et al. Inhibition of mTOR pathway sensitizes acute myeloid leukemia cells to aurora inhibitors by suppression of glycolytic metabolism. Mol Cancer Res 2013;11:1326-36.

23. Liu S, Cai X, Xia L, et al. Chloroquine exerts antitumor effects on NB4 acute promyelocytic leukemia cells and functions synergistically with arsenic trioxide. Oncol Lett 2018;15:2024-30.

24. Ordonez R, Fernandez A, Prieto-Dominguez N, et al. Ceramide metabolism regulates autophagy and apoptotic cell death induced by melatonin in liver cancer cells. J Pineal Res 2015;59:178-89.

25. Platzbecker U, Avvisati G, Cicconi L, et al. Improved Outcomes With Retinoic Acid and Arsenic Trioxide Compared With Retinoic Acid and Chemotherapy in Non-High-Risk Acute Promyelocytic Leukemia: Final Results of the Randomized Italian-German APL0406 Trial. J Clin Oncol 2017;35:605-12.

26. Norsworthy KJ, Altman JK. Optimal treatment strategies for high-risk acute promyelocytic leukemia. Curr Opin Hematol 2016;23:127-36.

27. Housman G, Byler S, Heerboth S, et al. Drug resistance in cancer: an overview. Cancers (Basel) 2014;6:1769-92.

28. Jeanne M, Lallemand-Breitenbach V, Ferhi O, et al. PML/RARA oxidation and arsenic binding initiate the antileukemia response of As2O3. Cancer Cell

Cite this article as: Wei X, Pu X, Yang S, Meng X, Chen X, Zhang Z, Sheng X, Xiang D, Zhang Y. Melatonin enhances arsenic trioxide-induced cytotoxicity by modulating autophagy in an acute promyelocytic leukemia cell line. Transl Cancer Res 2019;8(5):2079-2088. doi: 10.21037/tcr.2019.09.26
2010;18:88-98.

29. Nooshinfar E, Bashash D, Safaroghli-Azar A, et al. Melatonin promotes ATO-induced apoptosis in MCF7 cells: Proposing novel therapeutic potential for breast cancer. Biomed Pharmacother 2016;83:456-65.

30. Stehle JH, Saade A, Rawashdeh O, et al. A survey of molecular details in the human pineal gland in the light of phylogeny, structure, function and chronobiological diseases. J Pineal Res 2011;51:17-43.

31. Ju HQ, Li H, Tian T, et al. Melatonin overcomes gemcitabine resistance in pancreatic ductal adenocarcinoma by abrogating nuclear factor-kappaB activation. J Pineal Res 2016;60:27-38.

32. Bartsch C, Bartsch H, Fluchter SH, et al. Evidence for modulation of melatonin secretion in men with benign and malignant tumors of the prostate: relationship with the pituitary hormones. J Pineal Res 1985;2:121-32.

33. Tamarkin L, Cohen M, Roselle D, et al. Melatonin inhibition and pinealectomy enhancement of 7,12-dimethylbenz(a)anthracene-induced mammary tumors in the rat. Cancer Res 1981;41:4432-6.

34. Bojkova B, Kajo K, Kiskova T, et al. Metformin and melatonin inhibit DMBA-induced mammary tumorigenesis in rats fed a high-fat diet. Anticancer Drugs 2017. [Epub ahead of print].

35. Asghari MH, Ghobadi E, Moloudizargari M, et al. Does the use of melatonin overcome drug resistance in cancer chemotherapy? Life Sci 2018;196:143-55.

36. Parkhitko AA, Favorova OO, Henske EP. Autophagy: mechanisms, regulation, and its role in tumorigenesis. Biochemistry (Mosc) 2013;78:355-67.

37. Sui X, Chen R, Wang Z, et al. Autophagy and chemotherapy resistance: a promising therapeutic target for cancer treatment. Cell Death Dis 2013;4:e838.

38. Lee YJ, Won AJ, Lee J, et al. Molecular mechanism of SAHA on regulation of autophagic cell death in tamoxifenresistant MCF-7 breast cancer cells. Int J Med Sci 2012;9:881-93. 


\section{Supplementary}

A

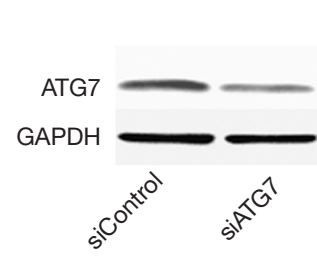

B

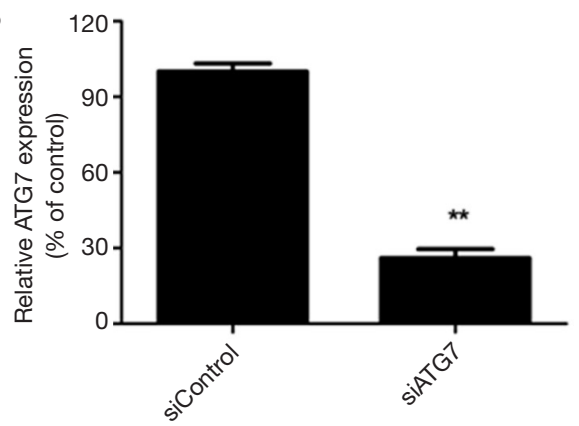

Figure S1 The efficiency of ATG 7 silencing. (A) Representative images, (B) quantitative analysis showing the efficiency of ATG 7 silencing. Each value was expressed as the mean \pm standard error of the mean $(n=3)$. ${ }^{* *} \mathrm{P}<0.01$ compared with the control siRNA (sc-Control) groups. 